\title{
Clinical Characteristics and Early Outcomes of Hospitalized COVID-19 Patients with End-Stage Kidney Disease in Saudi Arabia
}

\author{
Ali Hakami' \\ Mohammed Badedi $\mathbb{D D}^{2}$ \\ Mohammed Elsiddig' \\ Mohammed Nadeem' \\ Nada Altherwi ${ }^{1}$ \\ Raed Rayani' \\ Akram Alhazmi (D)
}

'Kidney Center, King Fahad Central Hospital, Jazan Health Affairs, Jazan, Saudi Arabia; ${ }^{2}$ Administration of Research \& Studies, Jazan Health Affairs, Jazan, Saudi Arabia
Correspondence: Ali Hakami

Tel +966505797663

Email alialhakami2003@yahoo.com
Background: The prognosis of the novel coronavirus disease 2019 (COVID-19) may be poor in patients with end-stage kidney disease (ESKD). Limited information is available on the clinical characteristics and outcomes of such patients in Arab countries. The present study aimed to address this gap.

Methods: This retrospective cohort study included 101 patients with ESKD who were hospitalized for COVID-19 between May 1, 2020 and December 31, 2020 at King Fahad Central Hospital (single center), Jazan Province, Saudi Arabia. Chi-square test, independent samples $t$-test, Mann-Whitney $U$-test, and Cox regression were performed in the statistical analysis.

Results: Of the 101 hospitalized COVID-19 patients with ESKD, 20 patients died (19.8\%). Patients aged $\geq 65$ years had a significant mortality risk. Mortality was higher in male patients $(70 \%)$ than in female patients $(30 \%)$. The most common comorbidities were hypertension $(88 \%)$, diabetes mellitus $(47 \%)$, and heart disease $(17 \%)$. The presence of diabetes and cardiovascular diseases along with ESKD increased the mortality risk [relative risk $(\mathrm{RR})=6.5$ and $\mathrm{RR}=3.8$, respectively]. The most frequently reported clinical symptoms were fever (50\%), shortness of breath (41\%), and cough (35\%). In total, $17 \%$ of the patients were admitted to the intensive care unit and required mechanical ventilation. Most patients had bilateral lung infiltrates (88\%). Hemoglobin levels and platelet counts were significantly lower in the deceased patients than in the surviving ones. Moreover, compared with the surviving patients, higher degree of lymphocytopenia, neutrophilia, ferritin, D-dimer, blood urea nitrogen, and aspartate transaminase were detected in the deceased patients. Septic shock $(20 \%)$ and respiratory failure $(19 \%)$ were the most prevalent complications resulting in death.

Conclusion: COVID-19 patients with ESKD have an increased risk of poor outcomes and mortality. The mortality risk increases with an increase in age and the presence of other comorbidities, such as diabetes and cardiovascular disease. Elevated levels of inflammatory markers correlate with disease severity and are associated with in-hospital mortality in this population.

Keywords: COVID-19, SARS-CoV-2, end-stage kidney disease, ESKD

\section{Introduction}

The novel coronavirus disease 2019 (COVID-19), caused by severe acute respiratory syndrome coronavirus 2 (SARS-CoV-2), has rapidly spread worldwide. ${ }^{1}$ The Kingdom of Saudi Arabia, which is the largest sovereign state in the Arabian Peninsula, is one of the most affected countries, with a high number of COVID-19 deaths being recorded in 
the Gulf Cooperation Council and the third highest number of confirmed cases being recorded in the Middle East. ${ }^{2}$ COVID-19 infected over 380,000 people and caused over 12,000 deaths in Saudi Arabia as of March 2021. ${ }^{3}$ Of these, over 6500 deaths occurred in Jazan Province, representing a $4 \%$ mortality rate. ${ }^{3}$

Patients with end-stage kidney disease (ESKD) are more vulnerable to COVID-19 as they are immunocompromised and require frequent hospital visits for hemodialysis sessions, which expose them to the risk of SARS-CoV-2 infection. In terms of disease severity, the most common factors associated with poor prognosis include advanced age and the presence of pre-existing comorbidities, such as chronic kidney disease. ${ }^{4,5}$ While acute respiratory failure due to diffuse alveolar damage is the main clinical characteristic of COVID-19, the kidneys are one of the most common extrapulmonary targets of the virus. $^{6}$ In line with this information, a previous study revealed that the mortality risk in patients with kidney disease was more than threefold higher than that in others. ${ }^{4}$ Thus, assessment of the clinical features and severity of COVID-19 in patients with ESKD is necessary for a better understanding and proper management of the disease. To our knowledge, very few published papers have reported the clinical outcomes of COVID-19 and its effects on ESKD. ${ }^{7-10}$ However, there is a need to increase the available evidence in this regard, particularly in Saudi Arabia, owing to genetic and ethnic differences among the populations. In addition, the clinical characteristics of COVID-19 patients with ESKD in Jazan Province, Saudi Arabia, have not been evaluated so far. The present study aimed to address this gap.

\section{Methodology Study Design and Setting}

This retrospective cohort study included 101 patients with ESKD who were diagnosed with COVID-19 and admitted to King Fahad Central Hospital, Jazan Province, Saudi Arabia, between May 1, 2020 and December 31, 2020. This hospital has the main kidney center that provides care services for patients with kidney disease in Jazan Province. Following the guidelines of the Saudi Center for Disease Prevention and Control, ${ }^{11}$ the diagnosis of COVID-19 was confirmed by the identification of viral RNA in nasopharyngeal swab samples using real-time reverse transcription polymerase chain reaction (LightCycler ${ }^{\circledR} 480$ Instrument II, Roche). The Jazan Health Ethics Committee (reference number: H-10-Z-073) granted ethical approval (no. 2035) for conducting the present study. The research complied with the Declaration of
Helsinki. Consent was waived as the data were anonymous and collected retrospectively (secondary data).

\section{Data Collection}

The data were collected retrospectively from medical records and included information about the patients' age, sex, smoking history, comorbidities, clinical symptoms, laboratory test results, radiological findings, treatment and dialysis, need for intensive care unit (ICU) admission, need for mechanical ventilation support, hospitalization duration, and outcomes (recovery or death). Laboratory tests were performed to assess the complete blood count, coagulation profile, and renal and hepatic functions at baseline (at $24 \mathrm{~h}$ of admission) and 24 $\mathrm{h}$ prior to recovery or death. The dates of COVID-19 diagnosis, hospital admission, and death were also recorded. The survival time during hospitalization (ie, the hospitalization duration) was defined as the period between hospital admission and recovery or death. The disease duration (in days) was defined as the period between the manifestation of clinical symptoms of COVID-19 and recovery or death. The criteria for recovery were based on the guidelines of the Ministry of Health, Saudi Arabia. Recovery was considered to have occurred when at least 3 days had passed after the resolution of fever and respiratory symptoms along with two negative polymerase chain reaction results obtained $\geq 24 \mathrm{~h}$ apart; alternatively, at least 10 days had to have passed since symptom onset. ${ }^{12}$ In accordance with the World Health Organization guidelines, ${ }^{13}$ the body mass index (BMI) was calculated as the weight in kilograms divided by the square of the person's height in meters. Individuals with $\mathrm{BMI} \geq 30 \mathrm{~kg} / \mathrm{m} 2$ were categorized as obese.

\section{Data Analysis}

Data entry and analysis were performed using the Statistical Package for the Social Sciences ${ }^{\circledR}$ software. ${ }^{14}$ Categorical variables are presented as percentages, while continuous variables are presented as the mean \pm standard deviation (SD) for normally distributed variables and as the mean \pm standard error of the mean (SEM) for non-normally distributed variables. The chi-square test was used to detect any significant associations between categorical variables. The independent samples $t$-test and Mann-Whitney $U$-test were used to compare the differences in mean values of normal and non-normal variables, respectively, between groups (adjusted for sex, age, and BMI). The Kaplan-Meier curve was used to estimate the survival rate during hospitalization. Univariate and multivariate Cox regression analyses were used to determine hazard ratios (HRs) with 95\% confidence intervals (CIs) for the outcomes. 
To determine significant pre-existing conditions leading to the outcomes of interest, all comorbidities were included in a model including age, sex, and BMI. All other parameters (laboratory test results and complications) were adjusted for age, sex, and BMI. Significance was set at $\mathrm{P}<0.05$.

\section{Results}

\section{Demographic Characteristics and Co-Morbidities}

Table 1 shows the demographic characteristics and comorbidities of the study population stratified according to sex and survival status. In the present study, 20 patients died of COVID-19, while 81 recovered. The mortality rate was thus $19.8 \%$. Patients with ESKD who were aged $\geq 65$ years had a significant mortality risk $(\mathrm{P}=0.03)$ (Table 1$)$. The mean age of the overall study population was $55 \pm 18.8$ years (range: 21-98 years). The mean age of the surviving patients was 52 years $(\mathrm{SD}=18.7)$, while that of the deceased patients was 67 years $(\mathrm{SD}=14.5)$. A higher number of male patients $(70 \%)$ than female patients (30\%) died of COVID-19 (Table 1). The most common comorbidities were hypertension $(88 \%)$, diabetes mellitus $(47 \%)$, heart disease $(17 \%)$, and obesity (14\%). The mortality risk in COVID-19 patients

Table I Demographic Characteristics and Co-Morbidities of COVID-I9 Patients with End-Stage Kidney Disease

\begin{tabular}{|c|c|c|c|c|}
\hline Variables & Overall $(N=101)$ & Survived $(\mathbf{N}=\mathbf{8} I)$ & Deceased $(\mathrm{N}=20)$ & $P$ \\
\hline \multicolumn{5}{|l|}{ Age } \\
\hline $21-45$ & $32(31.7 \%)$ & $30(37.0 \%)$ & $2(10.0 \%)$ & $0.03 *$ \\
\hline $46-64$ & 31 (30.7\%) & $25(30.9 \%)$ & $6(30.0 \%)$ & \\
\hline $65-98$ & $38(37.6 \%)$ & $26(32.1 \%)$ & $12(60.0 \%)$ & \\
\hline \multicolumn{5}{|l|}{ Sex } \\
\hline Male & $58(57.4 \%)$ & 44 (54.3\%) & 14 (70.0\%) & 0.20 \\
\hline Female & 43 (42.6\%) & 37 (45.7\%) & $6(30.0 \%)$ & \\
\hline \multicolumn{5}{|l|}{ Smoking } \\
\hline No & 99 (98.0\%) & 80 (98.8\%) & 19 (95.0\%) & 0.28 \\
\hline Yes & $2(2.0 \%)$ & $\mathrm{I}(\mathrm{I} .2 \%)$ & I (5.0\%) & \\
\hline \multicolumn{5}{|l|}{ Diabetes } \\
\hline No & 54 (53.5\%) & $50(61.7 \%)$ & $4(20.0 \%)$ & $0.001 *$ \\
\hline Yes & 47 (46.5\%) & 31 (38.3\%) & $16(80.0 \%)$ & \\
\hline \multicolumn{5}{|c|}{ Hypertension } \\
\hline No & $12(11.9 \%)$ & $12(14.8 \%)$ & 0 & $0.01 *$ \\
\hline Yes & 89 (88.1\%) & 69 (85.2\%) & $20(100 \%)$ & \\
\hline \multicolumn{5}{|l|}{ Obesity } \\
\hline No & 87 (86.1\%) & $70(86.4 \%)$ & 17 (85.0\%) & 0.87 \\
\hline Yes & 14 (13.9\%) & II (I3.6\%) & $3(15.0 \%)$ & \\
\hline \multicolumn{5}{|c|}{ Heart disease } \\
\hline No & 84 (83.2\%) & 7I (87.7\%) & $13(65.0 \%)$ & $0.01 *$ \\
\hline Yes & I7 (I6.8\%) & $10(12.3 \%)$ & 7 (35.0\%) & \\
\hline \multicolumn{5}{|c|}{$\begin{array}{l}\text { Number of } \\
\text { comorbidities }\end{array}$} \\
\hline 0 & 10 (9.9\%) & $10(12.3 \%)$ & 0 & $0.006^{*}$ \\
\hline 1 & 35 (34.7\%) & 32 (39.5\%) & $3(15.0 \%)$ & \\
\hline 2 & $38(37.6 \%)$ & $29(35.8 \%)$ & $9(45.0 \%)$ & \\
\hline$\geq 3$ & 18 (I7.8\%) & $10(12.3 \%)$ & $8(40.0 \%)$ & \\
\hline \multicolumn{5}{|c|}{ Co-infection } \\
\hline No & $96(95.0 \%)$ & $80(98.8 \%)$ & $16(80.0 \%)$ & $0.001 *$ \\
\hline Yes & $5(5.0 \%)$ & I (I.2\%) & 4 (20.0\%) & \\
\hline
\end{tabular}

Note: $*$ Significant results $(\mathrm{P}$ value $<0.05)$. 
with ESKD and diabetes mellitus was more than sixfold higher than that in the others $(\mathrm{RR}=6.5 ; \mathrm{P}=0.001)$ (Table 1). Moreover, the mortality risk in COVID-19 patients with ESKD and cardiovascular disease was fourfold higher than that in the others $(\mathrm{RR}=3.8 ; \mathrm{P}=0.010)$. Co-infection and the presence of three or more pre-existing comorbidities were also significantly associated with mortality in COVID-19 patients with ESKD (Table 1).

\section{Haemodialysis Characteristics}

Table 2 shows the type of hemodialysis and number of hemodialysis sessions received by COVID-19 patients with ESKD. The mean dialysis vintage was 3.9 years, and $64 \%$ of the patients had arteriovenous fistula access. In total, $83 \%$ of the patients received continuous renal replacement therapy (CRRT), while 68\% received two dialysis sessions per week (Table 2).

\section{Clinical Symptoms and Hospitalization Length of Stay}

The most frequently reported clinical symptoms in the hospitalized COVID-19 patients with ESKD were fever (50\%), shortness of breath (41\%), and cough (35\%); a small percentage of patients reported having diarrhea (10\%) (Table 3$)$. The prevalence of these symptoms was significantly higher in the deceased patients (Table 3). Most COVID-19 patients with ESKD (83\%) were admitted to a general medical ward, while
$17 \%$ were admitted to the ICU and required intubation (Table 3). The prevalence of ICU admission and intubation was also significantly higher in the deceased patients $(80 \%)$ (Table 3). The median duration between diagnosis and recovery was 9 days, while that between hospital admission and recovery was 7 days (Figure 1). The median duration from diagnosis to death, hospital admission to death, ICU admission to death, and intubation to death was $8.5,9,7.5$, and 7 days, respectively (Figure 1). Eight patients $(40 \%)$ who died had a do-not-resuscitate order in place at the time of death.

\section{Radiological and Clinical Laboratory Findings}

Chest X-rays revealed bilateral lung infiltrates and pulmonary opacity in most hospitalized COVID-19 patients with ESKD (88\%). All deceased patients had bilateral lung infiltrates and pulmonary opacity (100\%). Most surviving patients $(85 \%)$ had lung infiltrates and pulmonary opacity, $6 \%$ had plural effusion, and $6 \%$ had no abnormal chest $\mathrm{X}$-ray findings. There were no differences in the radiological findings between the surviving and deceased patients.

The clinical laboratory findings of the hospitalized COVID-19 patients with ESKD at admission and $24 \mathrm{~h}$ prior to recovery or death are depicted in Table 3. The hemoglobin levels and platelet counts were significantly lower in the deceased patients than in the surviving patients at admission and $24 \mathrm{~h}$ prior to death, respectively (Table 4). Typically,

Table 2 Hemodialysis Type and Sessions That COVID-19 Patients with End-Stage Kidney Disease Received

\begin{tabular}{|c|c|c|c|c|}
\hline Hemodialysis & Overall $(N=101)$ & Survived $(\mathbf{N}=8 \mathrm{I})$ & Deceased $(N=20)$ & $\mathbf{P}$ \\
\hline Vintage in year & $3.9 \pm 3.8$ & $3.9 \pm 3.6$ & $4.1 \pm 4.9$ & 0.485 \\
\hline \multicolumn{5}{|l|}{ Access } \\
\hline Arteriovenous fistula & 64 (64\%) & $5 \mathrm{I}(63.8 \%)$ & 13 (65\%) & $0.014 *$ \\
\hline Permcath & 34 (34\%) & $29(36.2 \%)$ & $5(25 \%)$ & \\
\hline Temporal line & $2(2 \%)$ & 0 & $2(10 \%)$ & \\
\hline \multicolumn{5}{|l|}{ Type } \\
\hline $\mathrm{CRRT}^{\wedge}$ & $84(83.2 \%)$ & $64(79.0 \%)$ & $20(23.8 \%)$ & 0.080 \\
\hline Conventional & $16(15.8 \%)$ & $16(19.8 \%)$ & 0 & \\
\hline Peritoneal & I (I\%) & I (I.2\%) & 0 & \\
\hline \multicolumn{5}{|l|}{ Sessions } \\
\hline Daily & $13(13.0 \%)$ & $4(5.0 \%)$ & $9(45 \%)$ & $<0.00 I^{*}$ \\
\hline Two per week & $68(68.0 \%)$ & 67 (83.8\%) & I (5\%) & \\
\hline Three per week & $19(19.0 \%)$ & 9 (II.2\%) & $10(50 \%)$ & \\
\hline \multicolumn{5}{|l|}{ Anticoagulant } \\
\hline Heparin & $53(52.5 \%)$ & 48 (59.3\%) & $5(25 \%)$ & $0.006 *$ \\
\hline Free heparin & 48 (47.5\%) & 33 (40.7\%) & I5 (75\%) & \\
\hline
\end{tabular}

Notes: *Significant results (P value $<0.05) ;{ }^{\wedge}$ Continuous Renal Replacement Therapy. 
Table 3 Clinical Symptoms and Signs on Admission Adjusted for Age, Sex and BMI

\begin{tabular}{|c|c|c|c|c|}
\hline Symptoms \& Signs & Overall $(N=101)$ & Survived $(\mathbf{N}=\mathbf{8} \mathrm{I})$ & Deceased $(\mathrm{N}=\mathbf{2 0})$ & $\boldsymbol{P}$ \\
\hline Difficulty breathing & $41(40.6 \%)$ & $22(27.2 \%)$ & $19(95.0 \%)$ & $<0.00 I^{*}$ \\
\hline Cough & 35 (34.7\%) & $26(32.1 \%)$ & $9(45.0 \%)$ & 0.28 \\
\hline Desaturation $\left(\mathrm{SpO}_{2}<94 \%\right)$ & $21(20.8 \%)$ & $8(9.9 \%)$ & $13(65.0 \%)$ & $<0.00 I^{*}$ \\
\hline Fever & 50 (49.5\%) & 36 (44.4\%) & $14(70.0 \%)$ & $0.04^{*}$ \\
\hline Confusion & $13(12.9 \%)$ & $4(4.9 \%)$ & $9(45.0 \%)$ & $<0.001 *$ \\
\hline Diarrhea & $10(9.9 \%)$ & $8(9.9 \%)$ & $2(10.0 \%)$ & 0.98 \\
\hline Temperature ${ }^{\wedge}\left(C^{\circ}\right)^{\wedge}$ & $36.8 \pm 0.4$ & $36.7 \pm 0.4$ & $36.8 \pm 0.6$ & 0.96 \\
\hline Systolic blood pressure $(\mathrm{mmHg})^{\wedge}$ & $140 \pm 24.1$ & $146 \pm 22.0$ & $128 \pm 24.2$ & $0.003^{*}$ \\
\hline Diastolic blood pressure $(\mathrm{mmHg})^{\wedge}$ & $74.5 \pm 15.1$ & $75 \pm 15.9$ & $70 \pm 14.9$ & 0.19 \\
\hline ICU admission & $17(16.8 \%)$ & $\mathrm{I}(1.2 \%)$ & $16(80 \%)$ & $<0.001 *$ \\
\hline Intubation & $17(16.8 \%)$ & $\mathrm{I}(\mathrm{I} .2 \%)$ & $16(80 \%)$ & $<0.00 I^{*}$ \\
\hline
\end{tabular}

Notes: *Significant results ( $\mathrm{P}$ value $<0.05$ ); ${ }^{\wedge}$ Independent-samples $t$-test and Mann-Whitney $U$-test compared means difference between groups according to the normality.

compared with the surviving patients, higher degree of leukocytosis, neutrophilia, lymphocytopenia, and neutrophil/lymphocyte ratio were observed at admission and $24 \mathrm{~h}$ prior to death in the deceased patients (Table 4). Moreover, levels of ferritin, D-dimer, blood urea nitrogen, and aspartate transaminase were higher $24 \mathrm{~h}$ prior to death in the deceased patients than in the surviving ones (Table 4).

\section{Associated Complications and Clinical Management}

In total, $76 \%$ of the COVID-19 patients with ESKD had no associated complications. However, septic shock (20\%)

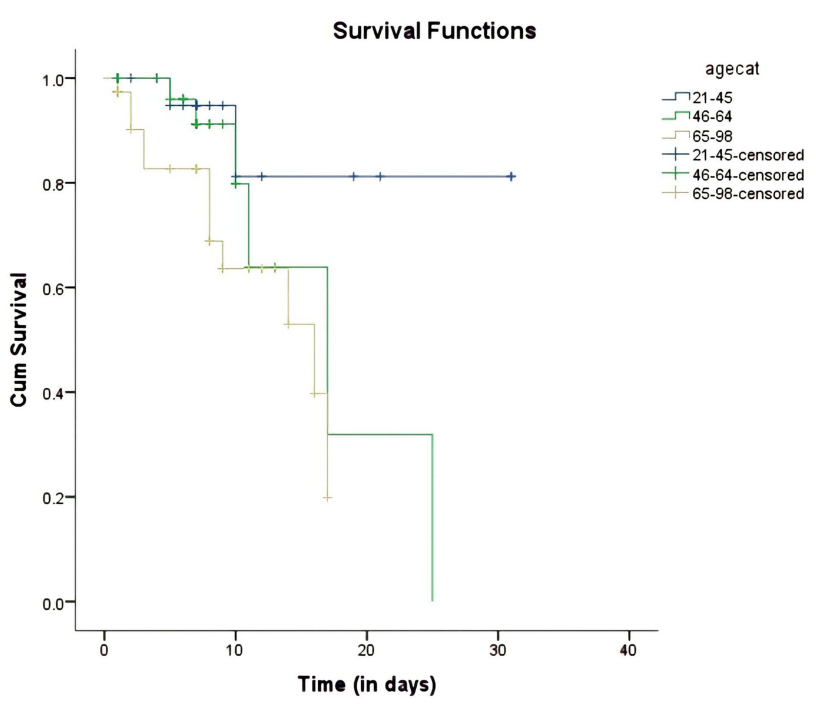

Figure I Kaplan-Meier survival analysis according to age groups. and respiratory failure and acute respiratory distress syndrome (19\%) were the most prevalent complications resulting in death $(\mathrm{P}<0.001)$.

Of the supportive medications provided to the patients in the present study, favipiravir (47\%), azithromycin (7\%), tocilizumab $(6 \%)$, hydroxychloroquine $(5 \%)$, methylprednisolone $(21 \%)$, deep vein thrombosis prophylaxis $(45 \%)$, and heparin $(51 \%)$ were the most significant ones.

\section{Findings of Kaplan-Meier Survival Analysis and Cox Regression Analysis}

Kaplan-Meier plots demonstrated that the mortality risk differed between age groups (Figure 1). The Kaplan-Meier survival curve revealed that COVID-19 patients with ESKD who were aged $\geq 65$ years had a significantly shorter survival duration than the others $(\mathrm{P}=0.03)$ (Figure 1).

The multivariate Cox proportional hazards regression model revealed statistically significant findings $(\mathrm{P}<0.001)$; it is provided in Table 5. It revealed that the mortality risk increased with age [HR 2.6 (95\% CI 1.3-5.1); P =0.008] and that the risk was significantly (twofold) higher in patients aged $\geq 65$ years than in the younger ones (Table 5). The mortality risk in COVID-19 patients with ESKD and cardiovascular disease was more than threefold higher than that in the others [adjusted HR 3.6 (95\% CI 1.3-10.1); P=0.016] (Table 5). Neutrophilia [HR 2.9 (95\% CI 1.4-6.3); P=0.004], lymphocytopenia [HR 3.4 (95\% CI 1.3-9.2); P =0.017], high D-dimer levels [HR 4.2 (95\% CI 1.6-9.2); $\mathrm{P}=0.005$ ], and high blood urea nitrogen levels [HR 1.4 (95\% CI 1.1-1.8); $\mathrm{P}=0.03$ ] were 
Table 4 Clinical Laboratory Findings on Admission and 24-Hr Prior Recovery or Death Adjusted for Age, Sex and BMI

\begin{tabular}{|c|c|c|c|c|c|c|}
\hline \multirow[t]{2}{*}{ Variables } & \multicolumn{3}{|c|}{ At Admission } & \multicolumn{3}{|c|}{ 24-Hr Prior to Recovery or Death } \\
\hline & $\begin{array}{l}\text { Survived } \\
(\mathbf{N}=81)\end{array}$ & $\begin{array}{c}\text { Deceased } \\
(N=20)\end{array}$ & $\mathbf{P}$ & $\begin{array}{l}\text { Survived } \\
(\mathrm{N}=\mathbf{8} \mathrm{I})\end{array}$ & $\begin{array}{l}\text { Deceased } \\
(\mathrm{N}=20)\end{array}$ & $\mathbf{P}$ \\
\hline \multicolumn{7}{|l|}{ Complete blood count } \\
\hline Hemoglobin (mmol/L) & $10.6 \pm 1.9$ & $9.8 \pm 1.3$ & $0.025^{*}$ & $9.8 \pm 0.43$ & $8.9 \pm 0.39$ & 0.180 \\
\hline White blood cell $\left(\times 10^{9} / \mathrm{L}\right)$ & $6.3 \pm 0.4$ & $9.1 \pm 1.3$ & $0.040 *$ & $8.6 \pm 0.7$ & $19.9 \pm 3.6$ & $0.003 *$ \\
\hline Platelets $\left(\times 10^{9} / \mathrm{L}\right)$ & $209 \pm 91.1$ & $256 \pm 119.2$ & 0.050 & $257 \pm 104.3$ & $186 \pm 108.2$ & $0.040^{*}$ \\
\hline Neutrophils (\%) & $62 \pm 14.7$ & $76 \pm 13.8$ & $<0.00 I^{*}$ & $66.9 \pm 3.2$ & $86.6 \pm 2.3$ & $<0.001 *$ \\
\hline Lymphocytes (\%) & $24.6 \pm 12.1$ & $14.6 \pm 10.0$ & $0.00 I^{*}$ & $21.2 \pm 2.8$ & $6.9 \pm 1.9$ & $0.001 *$ \\
\hline Neutrophil/lymphocyte ratio & $4.6 \pm 0.8$ & $12.5 \pm 16.1$ & $0.00 I^{*}$ & $6.6 \pm 1.2$ & $35.6 \pm 10.8$ & $<0.001 *$ \\
\hline Serum ferritin (pmol/L) & $1522 \pm 172$ & $2566 \pm 498$ & $0.016^{*}$ & $1763 \pm 282$ & $4066 \pm 1023$ & $0.015^{*}$ \\
\hline \multicolumn{7}{|l|}{ Coagulation profile } \\
\hline D-dimer (mcg/mL) & $1.6 \pm 1.7$ & $1.9 \pm 1.8$ & 0.511 & $2.9 \pm 1.8$ & $6.6 \pm 3.8$ & $0.028^{*}$ \\
\hline Prothrombin time (INR) & $1.2 \pm 0.1$ & $1.2 \pm 0.1$ & 0.365 & $1.4 \pm 0.2$ & $1.7 \pm 0.2$ & 0.192 \\
\hline \multicolumn{7}{|l|}{ Electrolytes } \\
\hline Sodium (mmol/L) & $136.3 \pm 4.0$ & $136.5 \pm 4.4$ & 0.911 & $\mid 34.1 \pm 4.2$ & $135.2 \pm 5.2$ & 0.423 \\
\hline Potassium (mmol/L) & $4.8 \pm 0.9$ & $5.2 \pm 1.3$ & 0.139 & $4.8 \pm 0.6$ & $5.4 \pm 1.5$ & 0.069 \\
\hline \multicolumn{7}{|l|}{ Renal profile } \\
\hline Creatinine $(\mu \mathrm{mol} / \mathrm{L})$ & $724 \pm 30.1$ & $785 \pm 74.3$ & 0.391 & $785 \pm 78.9$ & $658 \pm 81.4$ & 0.296 \\
\hline Blood urea nitrogen $(\mathrm{mmol} / \mathrm{L})$ & $18.2 \pm 7.7$ & $26.0 \pm 11.4$ & $<0.00 I^{*}$ & $27.1 \pm 12.0$ & $34.8 \pm 11.9$ & $0.04 I^{*}$ \\
\hline \multicolumn{7}{|l|}{ Liver profile } \\
\hline Alanine aminotransferase (unit/L) & $18.5 \pm 1.8$ & $26.7 \pm 6.8$ & 0.512 & $18.6 \pm 4.6$ & $95.3 \pm 30.5$ & $0.042 *$ \\
\hline Aspartate transaminase (unit/L) & $22.3 \pm 1.4$ & $69.3 \pm 22.2$ & $0.00 I^{*}$ & $27.2 \pm 5.8$ & $135.3 \pm 52.6$ & $0.008 *$ \\
\hline Bilirubin (umol/L) & $7.7 \pm 6.1$ & $7.6 \pm 2.9$ & 0.246 & $9.2 \pm 5.5$ & $16.3 \pm 8.4$ & $0.035^{*}$ \\
\hline Albumin $(g / L)$ & $36.5 \pm 5.9$ & $32.9 \pm 7.9$ & $0.037^{*}$ & $31.5 \pm 6.0$ & $29.4 \pm 4.5$ & 0.340 \\
\hline
\end{tabular}

Note: *Significant results $(\mathrm{P}$ value $<0.05)$.

also significant risk factors associated with mortality in hospitalized COVID-19 patients with ESKD (Table 5). The mortality risk was notably higher in patients who developed respiratory failure [HR $4.5(95 \% \mathrm{CI} 1.7-7.3) ; \mathrm{P}=0.02]$; these patients had a 4.5 -fold higher mortality risk than those without any complications (Table 5).

\section{Discussion}

The present study aimed to address the gap in knowledge regarding the clinical characteristics and outcomes of hospitalized COVID-19 patients with ESKD, Jazan Province, Saudi Arabia. We found that as the disease severity increased, the need for ICU admission and mechanical ventilation became very high in COVID-19 patients with ESKD. Furthermore, the mortality rate was high (20\%) in the present study; however, this rate is lower than that reported in New York (28\%), Manila (25\%), and Istanbul (31\%). ${ }^{7-9}$

In the present study, most hospitalized COVID-19 patients with ESKD were aged $\geq 65$ years and had two or more pre-existing comorbidities, such as hypertension, diabetes, and cardiovascular disease, which are common in patients with ESKD and are associated with increased disease severity and mortality risk. ${ }^{4,5,15}$ We found that the mortality risk in COVID-19 patients with ESKD and cardiovascular disease was fourfold higher than that in the others. These results are consistent with those of a previous study. ${ }^{7}$ Moreover, we found that the mortality risk in COVID-19 patients with ESKD and diabetes was more than sixfold higher than that in the others.

In terms of clinical symptoms, two studies conducted in Wuhan and Mumbai reported that most COVID-19 patients with ESKD have mild or no respiratory symptoms. ${ }^{16,17}$ However, in the present study, hospitalized COVID-19 patients with ESKD were symptomatic; the prevalence of symptoms was significantly higher in the deceased patients. These results are in line with those of previous studies. $^{7-9}$

The laboratory findings were predictive of severe COVID19 symptoms and the risk of early mortality. A study conducted in Wuhan hypothesized that patients with ESKD are 
Table 5 Predictors of Mortality and Intensive Care Unit (ICU) Admission in COVID-19 Patients

\begin{tabular}{|c|c|c|c|c|c|c|}
\hline \multirow[t]{2}{*}{ Predictors } & \multicolumn{3}{|c|}{ ICU Admission } & \multicolumn{3}{|c|}{ Mortality } \\
\hline & HR & $95 \% \mathrm{Cl}$ & p-value & HR & $95 \% \mathrm{Cl}$ & p-value \\
\hline Age $>65$ years & 3.5 & I.5-8.4 & $0.003 *$ & 2.6 & I.3-5.I & $0.008 *$ \\
\hline Sex & 2.1 & $0.2-2.4$ & 0.220 & 2.1 & $0.8-5.9$ & 0.149 \\
\hline Smoking & 2.4 & $0.3-5.8$ & 0.451 & 1.9 & $0.1-4.3$ & 0.552 \\
\hline \multicolumn{7}{|l|}{ Comorbidities } \\
\hline Obesity & I.I & $0.9-1.2$ & 0.439 & 1.8 & $0.5-6.3$ & 0.382 \\
\hline Diabetes & 2.5 & $0.7-9.8$ & 0.285 & 1.9 & $0.6-6.3$ & 0.249 \\
\hline Cardiovascular disease & 1.7 & $0.5-6.2$ & 0.427 & 3.6 & $1.3-10.1$ & $0.016^{*}$ \\
\hline \multicolumn{7}{|l|}{ Laboratory investigations } \\
\hline Hemoglobin & 1.3 & $0.8-2.3$ & 0.237 & 1.1 & $0.84-1.4$ & 0.503 \\
\hline White blood cell & 1.4 & $0.9-2.2$ & 0.093 & 1.6 & I.3-2.4 & 0.064 \\
\hline Platelets & 1.0 & $0.7-1.6$ & 0.64 & 1.2 & $0.8-2.1$ & 0.230 \\
\hline Neutrophils & 1.7 & $0.9-3.1$ & 0.110 & 2.9 & $1.4-6.3$ & $0.004 *$ \\
\hline Lymphocytes & 1.6 & $0.7-3.6$ & 0.241 & 3.4 & $1.3-9.2$ & $0.017^{*}$ \\
\hline $\mathrm{SpO}_{2}>95 \%$ & 2.3 & $0.2-3.1$ & $0.042 *$ & 1.9 & $1.1-3.1$ & $0.024^{*}$ \\
\hline D-dimer & 2.2 & $0.8-5.3$ & $0.013^{*}$ & 4.2 & $1.6-9.2$ & $0.005^{*}$ \\
\hline Blood urea nitrogen & 1.0 & $0.9-1.1$ & 0.848 & 1.4 & $1.1-1.8$ & $0.037^{*}$ \\
\hline Aspartate transaminase & I.I & $0.9-1.2$ & 0.081 & 1.1 & $1.0-1.8$ & $0.033^{*}$ \\
\hline \multicolumn{7}{|l|}{ Associated complications } \\
\hline Respiratory failure/ARDS & 3.9 & $1.3-6.9$ & $0.032 *$ & 4.5 & I.7-7.3 & $0.022^{*}$ \\
\hline Septic shock & 1.9 & $0.7-2.9$ & 0.089 & 2.3 & $0.9-4.2$ & 0.064 \\
\hline
\end{tabular}

Notes: *Comorbidities adjusted for one another + age, BMI and sex; Lab investigations were adjusted for age, BMI and Sex; Significant results (P value <0.05).

incapable of mounting a robust immune response that may lead to cytokine storm syndrome, which is associated with increased disease severity and mortality. Most of the patients in that study had mild disease, and none were admitted to the ICU. ${ }^{16}$ However, the findings of the present study were different. The white blood cell count was elevated at admission and was significantly higher in the deceased patients than in the surviving ones. The increase in the white blood cell count correlated with disease severity. ${ }^{18}$ In addition, the neutrophil count was higher and the lymphocyte count was lower in the deceased patients than in the surviving ones. As lymphocytopenia is associated with the inflammatory process (cytokine storm syndrome), it can be used to predict disease severity. ${ }^{19}$ These findings are consistent with those of previous studies, which have reported that elevated levels of inflammatory markers are associated with increased disease severity and worse outcomes, regardless of the immunosuppression observed in patients with ESKD. ${ }^{7-10}$ An increase in serum ferritin levels was observed in the deceased patients in the present study. This finding may be confirmed by the presence of severe inflammation, as ferritin is a positive acute-phase protein. ${ }^{20}$ A marked increase in D-dimer levels was also noted in the deceased patients in the present study. An increase in D-dimer levels is associated with high levels of fibrin degradation products and low antithrombin activity, in addition to the risk of thrombotic and hemorrhagic complications. ${ }^{21,22}$

Respiratory failure and acute respiratory distress syndrome were the most prevalent complications resulting in death in patients with ESKD in the present study. A similar finding has been reported previously. ${ }^{7,23}$ Human airway epithelia express angiotensin-converting enzyme 2 (ACE2), a host cell receptor for SARS-CoV-2. Of all organs, the lungs are most impacted by SARS-CoV-2 infection. ${ }^{24}$ In a previous study, pathological findings indicated that patients whose lungs were infected with SARS$\mathrm{CoV}-2$ presented with acute respiratory distress syndrome, pulmonary hyaline membrane formation, and pneumocyte desquamation. ${ }^{25}$ Most of these risk factors are linked, in varying degrees, to the progression of acute respiratory distress syndrome secondary to SARS-CoV-2. Moreover, they contribute to the exacerbation of pre-existing chronic inflammation, which then progresses to result in a cytokine storm and the rapid impairment of endothelial function. 


\section{Conclusion}

COVID-19 patients with ESKD have an increased risk of poor outcomes and mortality. The mortality risk increases with an increase in age and the presence of other comorbidities, such as diabetes and cardiovascular disease. Elevated levels of inflammatory markers correlate with disease severity and are associated with in-hospital mortality in this population.

\section{Data Sharing Statement}

The data that support the findings of this study are available on request from the corresponding author, [Ali Hakami].

\section{Ethics Approval}

The Jazan Health Ethics Committee (Reference number: H-10-Z-073) granted ethical approval (No. 2035) for the study to be conducted, and the research complied with the Declaration of Helsinki. Consent was waived as data were anonymous and collected retrospectively (secondary data).

\section{Disclosure}

The authors report no conflict of interests in this work.

\section{References}

1. World Health Organization (WHO). Coronavirus Disease (COVID19): Weekly Epidemiological Update WHO. Geneva: World Health Organization; 2020.

2. Dong E, Du H, Gardner L. An interactive web-based dashboard to track COVID-19 in real time. Lancet Infect Dis. 2020;20(5):533-534. doi:10.1016/S1473-3099(20)30120-1

3. Ministry of Health (MOH). Coronavirus Disease (COVID-19): Daily Report Update. Riyadh: MOH; 2020.

4. Badedi M, Makrami A, Alnami A. Co-morbidity and blood group type risk in coronavirus disease 2019 patients: a case-control study. J Infect Public Health. 2021;14(4):550-554. doi:10.1016/j.jiph.2020.12.035

5. Badedi M, Darraj H, Alnami A, et al. Epidemiological and Clinical Characteristics of Deceased COVID-19 Patients. Int J Gen Med. 2021;14:3809-3819. doi:10.2147/IJGM.S320713

6. Puelles V, Lutgehetmann M, Lindenmeyer M, et al. Multiorgan and Renal Tropism of SARS-CoV-2. N Engl J Med. 2020;383(6):590-592. doi:10.1056/NEJMc2011400

7. Fisher M, Yunes M, Mokrzycki MH, Golestaneh L, Alahiri E, Coco M. Chronic hemodialysis patients hospitalized with COVID-19short-term outcomes in Bronx, New York. J Kidney. 2020;3601 (8):755-762. doi:10.34067/KID.0003672020

8. Tomacruz I, So P, Pasilan R, Camenforte J, Duavit M. Clinical Characteristics and Short-Term Outcomes of Chronic Dialysis Patients Admitted for COVID-19 in Metro Manila, Philippines. Int J Nephrol Renovasc Dis. 2021;14:41-51. doi:10.2147/JJNRD. S287455
9. Kocak S, Kayalar A, Karaosmanoglu H, Yilmaz M. COVID-19 in hemodialysis patients: a single-center experience in Istanbul. Int Urol Nephrol. 2021;3:1-13.

10. Tortonese S, Scriabine I, Anjou L, et al. COVID-19 in patients on maintenance dialysis in the Paris Region. Kidney Int Rep. 2020;5 (9):1535-1544. doi:10.1016/j.ekir.2020.07.016

11. Saudi Center for Disease Prevention and Control (Weqaya). Laboratory Diagnosis of COVID-19 in Suspected Cases; 2020. Available from: https://covid19.cdc.gov.sa/professionals-healthworkers/laboratory-diagnosis/. Accessed 12 Oct 2020.

12. Saudi Center for Disease Prevention and Control. COVID-19 guidelines. Riyadh: Saudi Center for Disease Prevention and Control; 2020.

13. World Health Organization (WHO). Corticosteroid for COVID-19. Geneva: WHO; 2020.

14. BM Corp. IBM SPSS Statistics for Windows. NY: IBM Corp; 2012.

15. Zhou F, Yu T, Du R, et al. Clinical course and risk factors for mortality of adult inpatients with COVID-19 in Wuhan, China: a retrospective cohort study. Lancet. 2020;395:1054-1062. doi:10.1016/S0140-6736(20)30566-3

16. Ma Y, Diao B, Lv X, et al. COVID-19 in hemodialysis (HD) patients: report from one HD center in Wuhan, China. medRxiv. 2020. doi:10.1101/2020.02.24.20027201

17. Trivedi M, Shingada A, Shah M, Khanna U, Karnik ND, Ramachandran R. Impact of COVID-19 on maintenance haemodialysis patients: the Indian scenario. Nephrology. 2020;25(12):929-932. doi:10.1111/nep.13760

18. Huang C, Wang Y, Li X, et al. Clinical Features of Patients Infected with 2019 Novel Coronavirus in Wuhan, China. Lancet. 2020;395:497-506. doi:10.1016/S0140-6736(20)30183-5

19. Tan L, Wang Q, Zhang D, et al. Lymphopenia Predicts Disease Severity of COVID-19: a Descriptive and Predictive Study. Signal Transduct Target Ther. 2020;5:33. doi:10.1038/s41392-020-0148-4

20. Lippi G, Mattiuzzi C. Hemoglobin Value May Be Decreased in Patients with Severe Coronavirus Disease 2019. Hematol Transfus Cell Ther. 2020;42:116-117. doi:10.1016/j.htct.2020.03.001

21. Han H, Yang L, Liu R, et al. Prominent Changes in Blood Coagulation of Patients with SARS-CoV-2 Infection. Clin Chem Lab Med. 2020;58:1116-1120. doi:10.1515/cclm-2020-0188

22. Tang N, Li D, Wang X, Sun Z. Abnormal Coagulation Parameters Are Associated with Poor Prognosis in Patients with Novel Coronavirus Pneumonia. J Thromb Haemost. 2020;18:844-847. doi: $10.1111 /$ jth. 14768

23. Stefan G, Mehedinti A, Andreiana I, et al. Clinical features and outcome of maintenance hemodialysis patients with COVID-19 from a tertiary nephrology care center in Romania. Ren Fail. 2021;43(1):49-57. doi:10.1080/0886022X.2020.1853571

24. Li W, Moore M, Vasilieva N, et al. Angiotensin-converting enzyme 2 is a functional receptor for the SARS coronavirus. Nature. 2003;426 (6965):450-454. doi:10.1038/nature02145

25. Xu Z, Shi L, Wang Y, et al. Pathological findings of COVID-19 associated with acute respiratory distress syndrome. Lancet Respir Med. 2020;8(4):420-422. doi:10.1016/S2213-2600(20)30076-X 


\section{Publish your work in this journal}

The International Journal of General Medicine is an international, peer-reviewed open-access journal that focuses on general and internal medicine, pathogenesis, epidemiology, diagnosis, monitoring and treatment protocols. The journal is characterized by the rapid reporting of reviews, original research and clinical studies across all disease areas. The manuscript management system is completely online and includes a very quick and fair peer-review system, which is all easy to use. Visit http://www.dovepress.com/ testimonials.php to read real quotes from published authors.

Submit your manuscript here: https://www.dovepress.com/international-journal-of-general-medicine-journal 